\title{
Os discursos do etnólogo, do filósofo e do ficcionista na estrutura do romance Nove noites Cid Ottoni Bylaardt ${ }^{1}$
}

Nove noites é uma narrativa singular dentro do panorama da literatura brasileira contemporânea. Embora a enunciação se localize no final do século $\mathrm{XX}$, o romance contém vários elementos ligados à velha noção de identidade cultural brasileira, em seu confronto com a cultura modelar, notadamente europeia e norte-americana, salientando a dependência da cultura colonial e subdesenvolvida. Pensemos nas sociedades primitivas aí encenadas, os indígenas; as relações tensas entre eles e os brancos, quando não servis, humilhantes; a impaciência do branco em relação a eles. Todo esse ambiente de dívida cultural, entretanto, não contribui para consolidar a narrativa do romance como um discurso impositivo ou categórico.

Entre outras estratégias formais, a escritura ameniza as determinações por meio da pluralidade de vozes que se manifestam na narrativa, a começar pela presença de dois narradores, cujas enunciações guardam entre si um intervalo de mais de sessenta anos. Além dessas vozes, há cartas, poemas, entrevistas.

A voz inicial, que depois se reconhece como sendo de Manoel Perna, parece advertir o leitor de que o conceito de verdade ali veiculado é instável, longe das certezas a que nossa inteligência ocidental está acostumada: "Vai entrar numa terra em que a verdade e a mentira não têm mais os sentidos que o trouxeram até aqui" (Carvalho, 2002, p. 7). Essa voz parece dialogar de alguma maneira com a pergunta e a resposta enunciadas por Maurice Blanchot no capítulo "Connaissance de l'inconnu", de L'entretien infini: "Que é um filósofo? É alguém que tem medo" (Blanchot, 1969, p. 70, tradução nossa). Antigamente, dizia-se que um filósofo é um homem que se espanta. Blanchot reformula a resposta, atribuindo-lhe o medo, a angústia de se defrontar com o não conhecível que demanda o conhecimento. No procedimento do conhecer, em geral, o sujeito se apropria do objeto e reduz o desconhecido ao conhecido. Essa é uma forma segura de pensamento e discurso, coerentes com a metafísica ocidental. Não obstante, nosso objeto pode, em muitos casos, situar-se

\footnotetext{
${ }^{1}$ Doutor em estudos literários e professor da Universidade Federal do Ceará (UFC), Fortaleza, CE, Brasil. E-mail: cidobyl@ig.com.br
} 
fora de nossos limites. Temos então com o objeto uma relação de não poder, e talvez só o poeta, alvo de desconfiança do filósofo, possa exercer o desejo de conhecer o não conhecível. Não como necessidade, carência a ser suprida; não como amor, que pressupõe a união; mas como desejo, o que não pode ser satisfeito, o que permanece inacessível e exterior. Como disse René Char: "O poema é o amor realizado do desejo que permanece desejo" (apud Blanchot, 1969, p. 76, tradução nossa). Assim, a atitude do filósofo diante do desconhecido ou da impossibilidade é o medo, diferente da disposição do poeta. Algo semelhante ocorre com as declarações iniciais do engenheiro de Carolina, que parecem sugerir um confronto com o não conhecível.

Jacques Derrida (1967) retoma a discussão que envolve o ser humano e o conhecimento, bem como suas implicações sobre os conceitos de verdade, no texto "A estrutura, o signo e o jogo no discurso das ciências humanas", e fala de uma ruptura e um redobramento na história do conceito de estrutura. Na episteme ocidental, esse conceito se sustenta em um centro, que lhe confere coerência e equilíbrio e, sobretudo, limita o jogo da estrutura, estabelecendo os sentidos que se pretendem inquestionáveis da metafísica ocidental. O centro é ao mesmo tempo coerente e paradoxal, uma vez que se situa tanto dentro quanto fora da estrutura. Os fundamentos que norteiam os movimentos da estrutura em seu centro - e que provêm do centro da totalidade, que se situa fora da estrutura - conduzem o pensamento a uma ilusão provocada pela natureza da linguagem, a ilusão de ver no signo a presença da "coisa" ou do "conceito". Essa ilusão é necessária para que a angústia do não conhecível seja dominada pela certeza tranquilizadora assegurada pela história do sentido. É a isso que Derrida chama metafísica da presença. A referida ilusão assegura o funcionamento do signo como tal: afinal, ele está no lugar de alguma outra coisa, e, embora na plena presença do signo, o conceito de algo é definitivamente adiado. Para ele, o signo carrega não apenas o traço daquilo que substitui mas também o traço daquilo que ele não é, ou seja, precisamente da diferença. Em suma, o signo é caracterizado pelo adiamento (da presença) e pela diferença (relativamente a outros signos). Essas duas características estão sintetizadas no conceito de différance.

Essa lei do desejo do centro, entretanto, começa a ser abalada quando a estrutura passa a ser pensada, repetida, ocorrendo a ruptura. Daí, a repetição provoca disrupção. A lei que comanda os 
deslocamentos e substituições no processo de significação é repensada, de modo que a lei da presença central pode passar a ser vista não mais como algo natural. A linguagem desperta a ideia de que na verdade não há centro, não há realmente um significado central, originário e transcendental, e este só se sustenta dentro de um sistema de diferenças. A ausência de significação "transcendental" no centro amplia indefinidamente o campo e o jogo da significação

Os primeiros detratores desse conceito clássico de estrutura foram: a crítica nietzschiana da metafísica, em que os conceitos de jogo, interpretação e signo (signo sem verdade presente) substituem os conceitos de ser e verdade; a crítica freudiana da presença em si, consciência a si, identidade a si, sujeito a si, da proximidade ou propriedade a si; a destruição heideggeriana da metafísica, da ontoteologia, da determinação do ser como presença. A metafísica é abalada pela própria linguagem da metafísica, uma vez que não dispomos de nenhum léxico e nenhuma sintaxe que seja estranha a ela. Nietzsche, Freud e Heidegger operaram com conceitos herdados da metafísica, os quais por sua vez trazem com eles, em sua linguagem, a própria metafísica. Eis o redobramento anunciado por Derrida: a crítica da metafísica conserva como instrumento aquilo cujo valor de verdade ele critica.

Passando ao romance, este é um gênero cuja progressão joga em torno de um centro, ainda que contenha digressões e outros caminhos. O próprio conceito de romance liga-se a uma noção de centro. Em Nove noites, o núcleo da narrativa pode ser considerado, de uma perspectiva de gênero, a elucidação do suicído do jovem etnólogo Buell Quain no norte do Brasil em 1939. A expectativa de quem lê, assim, é "centrada" nessa conclusão, por mais que o leitor arguto saiba que a fabulação romanesca certamente lhe reservará surpresas e imprevistos. Pode-se pensar, então, que esse centro de alguma forma fecha o jogo que ele próprio abre e torna possível. Pensemos num conceito metafísico do gênero romance, cuja estrutura centrada autoriza os analistas a lhe atribuírem traços que fixam a forma.

Retomando a contradição apontada por Derrida - a de que, ao mesmo tempo que sustenta uma estrutura, ou seja, está dentro dela, o centro tem sua força regulada de fora -, as repetições, as substituições, as transformações, as permutas que a estrutura permite estão sempre condicionadas a uma história do sentido, a uma presença que o antecipa. É evidente que o romance, em seus desdobramentos, tende a 
se livrar das determinações do centro, chegando mesmo a ser acusado em determinado momento, por alguém do porte de Sartre, de estar sendo destruído pelas inovações dos idealizadores do nouveau roman lá pelos idos dos anos 1950. Na opinião de Walter Benjamin, o advento do romance provoca uma lamentável devastação na narrativa, porque o romance é livro, é página impressa, seu leitor é solitário, o texto "nem procede da tradição oral nem a alimenta" (Benjamin, 1994, p. 201). Blanchot, ao invés, nega a monstruosidade do romance, salvadas as exceções, considerando-o "um monstro bem educado e muito domesticado" (Blanchot, 1998, p. 278, tradução nossa), que preserva sua preponderância, a despeito das aparentes liberdades e audácias, com a "a segurança discreta de suas convenções" e "a riqueza de seu conteúdo humanista" (Blanchot, 1998, p. 278, tradução nossa), e reivindica o estilhaçamento da literatura, a dispersão que a fará aproximar-se de si mesma. Enquanto Benjamin lastima as ousadias do romance, que cessa de dialogar com o mundo exterior, tornando-se interioridade pura, Blanchot defende e profetiza a passagem do romance para o exterior (que não é o mundo exterior, mas o mundo do fora), tornando-se o discurso que se desenvolve a partir de si mesmo, eliminando o caráter retórico, mitológico ou ideológico da literatura.

Apesar de todas as incertezas e contradições que pesam sobre o gênero romance, é interessante constatar que nem a arte escapa às verdades da cultura iluminista, colocadas em questão por Derrida.

Derrida atribui à etnologia um lugar privilegiado entre as ciências humanas pelo fato de ter nascido como ciência ao deslocar a cultura europeia de seu lugar. Ela tem seu lugar na denúncia da história da metafísica. Ambas pertencem à mesma época. A etnologia é uma ciência europeia, utiliza os conceitos da tradição e as premissas do etnocentrismo. Depende da responsabilidade crítica do pesquisador colocar em questão essas premissas, senso crítico necessário à déconstruction dessa herança. Aqui Derrida utiliza o termo que se fixou posteriormente como nome genérico de seu pensamento: desconstrução.

Ao mencionar a etnologia, Derrida faz referência aos textos de Claude Lévi-Strauss, que parecem manifestar a escolha de uma linguagem crítica e uma crítica da linguagem das ciências humanas. O par escolhido por Strauss para acionar o movimento questionador foi natureza $\times$ cultura, oposição mais antiga do que Platão, que remonta pelo menos à sofística. Lévi-Strauss parte de definições tradicionais do par 
opositivo, dando-lhe crédito, mas, ao mesmo tempo, desconfiando dele. O etnólogo encontra então um escândalo que abala a oposição: $a$ proibição do incesto. De um lado, é universal (natural?); de outro, é uma proibição, uma norma (cultural?). O escândalo está no interior do sistema binário, que dá crédito à oposição entre natureza e cultura. Só se pode pensar no fracasso da oposição e sua condição de escândalo caso se acredite no sistema de dicotomias.

Suponhamos que pudéssemos pensar em Nove noites como um romance policial. Evidentemente, ele não o é, considerando as determinações do gênero, mas relacionemos essa suposição à maneira como Lévi-Strauss, segundo Derrida, trata o par opositivo natureza/cultura, desprovendo-o do caráter de verdade, mas preservando sua condição de auxiliar metodológico. Não descartemos, portanto, a ideia "metafísica" do romance policial.

O exemplo do par natureza x cultura evidencia o fato de a linguagem carregar sua própria crítica. O que Lévi-Strauss faz, segundo Derrida, é tentar conservar esses conceitos, como auxiliares úteis, e lançar mão deles aqui e ali na medida das necessidades, "como utensílios que ainda podem servir" (Derrida, 1967, p. 417, tradução nossa). Ao empreender a crítica, ele separa método de verdade: a distinção entre natureza e cultura tem valor de método, "à falta de significação histórica aceitável" (Derrida, 1967, p. 417, tradução nossa), mas soçobra como verdade. Seu valor metodológico "não é afetado pelo não valor "ontológico'" (Derrida, 1967, p. 417, tradução nossa). Sua atitude é a do bricoleur, o que reutiliza, reaproveita. Assim, toda linguagem é, no fundo, bricolagem. Se o engenheiro é, metodologicamente, o oposto do bricoleur, e se a verdade do engenheiro é impossível, porque inventar uma nova língua seria brincar de Deus, então a própria existência do bricoleur está ameaçada no sistema binário.

Logo no primeiro capítulo, a voz narrativa, que identificamos mais tarde como sendo do personagem Manoel Perna, o qual faz seu relato num tempo próximo ao da morte do etnólogo, anuncia o crime, ocorrido em 1939:

No dia 9 de agosto daquele ano, cinco meses depois de ele ter chegado a Carolina, uma comitiva de vinte índios entrou na cidade no final da tarde. Traziam a triste notícia e, na bagagem, os objetos de uso pessoal do dr. Buell, que eu mesmo recebi e contei, com lágrimas nos olhos: dois livros de música, uma Bíblia, um 
par de sapatos, um par de chinelos, três pijamas, seis camisas, duas gravatas, uma capa preta, uma toalha, quatro lenços, dois pares de meias, um suspensório, dois ternos de brim, dois ternos de casimira, duas cuecas e um envelope com fotografias. O seu retrato não estava entre elas (Carvalho, 2002, p. 11).

Temos aí então a pressuposição de uma estrutura e seu centro, o crime, que deflagra uma investigação e uma expectativa de elucidação, apontando para o romance policial como auxiliar metodológico. A expectativa não se desfaz quando o segundo enunciador, mais de sessenta anos depois da morte do etnólogo, reapresenta sua morte e por algum motivo parece disposto a buscar a solução. Esse enunciador é um jornalista que acaba se envolvendo com o mundo da antropologia para tentar desvendar o mistério da morte de Buell Quain. A intervenção do jornalista, inclusive, parece dar mais consistência à própria ideia de investigação, apesar da distância cronológica do evento, porque o relato de Manoel Perna não consegue sustentar nenhuma direção plausível no jogo dos elementos da estrutura.

O leitor, apesar de ter uma certa esperança de que Manoel Perna traga alguma luz sobre a história, decepciona-se com o discurso do engenheiro de Carolina. Seu relato parece dirigido a alguém que possivelmente vai chegar à cidadezinha de Carolina e que tem alguma ligação com Quain. De início, o primeiro narrador avisa: "Vai entrar numa terra em que a verdade e a mentira não têm mais os sentidos que o trouxeram até aqui. Pergunte aos índios" (Carvalho, 2002, p. 7).

Manoel Perna conserva a narrativa na escuridão das nove noites regadas a cachaça em que ele e o etnólogo conversavam, relato que de alguma forma mantém o leitor esperançoso de que contenha alguma informação que possa ser usada pelo jornalista em sua investigação. É curioso que o depoimento de Manoel Perna nem deveria estar ali, uma vez que os próprios filhos afirmaram que ele não havia deixado nada escrito sobre a morte do então amigo Buell Quain. E em nenhum momento se elucida a presença ali daquele discurso fantasma.

Talvez a maior virtude desse romance, sua trapaça essencial, seja a tensão localizada na linguagem, no confronto de discursos que sinalizam para uma resolução, mas, ao mesmo tempo, dão ao leitor a impressão de que esta está cada vez mais longe. O distanciamento que a narrativa provoca entre a investigação e a possibilidade de desfecho, entretanto, parece não desanimar o leitor, que, no decorrer dos 
desacertos, continua a esperar a grande verdade que vai esmagar todas as incertezas, mantendo a força da intriga.

Uma das estratégias textuais que mantêm a tensão é o fato de que o jornalista em nenhum momento - a não ser nas últimas páginas declara estar escrevendo um romance, mantendo em suspenso a definição do gênero textual. Em sua busca da verdade, o que ele faz é ouvir, ouvir, ouvir. É longa a lista dos que ele ouve. Inicialmente, ele lê o artigo que menciona o nome de Buell Quain, cujas cartas e depoimentos vasculhou cuidadosamente. Ouve ainda a antropóloga que escreveu o artigo em que menciona a morte de Quain; a filha da antropóloga Maria Júlia, que havia flertado com Quain; uma moça que lia livros para os velhos no asilo; o professor Luiz de Castro Faria, que integrou a expedição de Lévi Strauss e que conhecera Buell Quain; o próprio Lévi Strauss, em entrevista em Paris; o rapaz que lia histórias para o velho fotógrafo na enfermaria do hospital; os filhos de Manoel Perna, Francisco e Raimunda; o filho do fotógrafo nos Estados Unidos; e, sobretudo, ouviu sua própria memória, da infância à idade adulta recente, aparentemente tentando atar as pontas das histórias ou simulando a tentativa. Ele ouve também textos literários que não o auxiliam muito em sua tarefa: Drummond, Francis Ponge, Herman Melville, Joseph Conrad. Não há pontas nem retalhos a serem atados; o texto caminha para a errância. Outra audição importante: ao ler inicialmente a notícia em um jornal, ele ouviu o som de um nome que desencadeou a demanda.

Uma questão permanece indeterminada: teria ele ouvido Manoel Perna? Ele afirma ter lido a carta que Quain escreve a Manoel Perna, a carta que Perna escreve a Heloísa Alberto Torres, diretora do Museu Nacional. Mas a pergunta que não tem resposta é: teria o relator que se diz jornalista, o investigador do futuro, lido o depoimento de Manoel Perna que faz contraponto com o dele próprio nas páginas do livro? Considerando que a diferença de tempo entre as duas escritas é de mais de meio século, o leitor tem a tendência de considerar o depoimento de Perna como uma espécie de relato auxiliar, possivelmente um auxiliar metodológico nos termos de Derrida e Lévi-Strauss, que de alguma forma teria chegado ao narrador jornalista para deitar luz à sua investigação. Entretanto, esse relato noturno, que inclusive dá nome ao livro, não vem à luz, nem como possibilidade de desvendamento do caso, nem como texto de suporte ao jornalista: os filhos de Manoel Perna 
"garantiram que ele não deixou nenhum papel ou testamento, nenhuma palavra sobre Buell Quain" (Carvalho, 2002, p. 134). Numa inversão surpreendente da situação da carta a cujo conteúdo ninguém teve acesso, o que é algo mais plausível, temos agora todo um texto que contraponteia com outro no romance e que jamais foi escrito; sua inexistência é, inclusive, assumida pelo narrador-jornalista. Nesse momento, o leitor descobre atônito que, mesmo que Manoel Perna venha a desvelar de alguma forma em sua carta-testamento o segredo da carta não lida ou qualquer informe esclarecedor, tal depoimento não valerá de nada, o que provoca um duro golpe em suas esperanças; ele, que, apenas ele, tem acesso às palavras de Manoel Perna.

Conclui-se então que boa parte da narrativa, a que tem como enunciador o engenheiro de Carolina, é desautorizada pela própria ficção. A incerteza, entretanto, não se restringe às fantasias discursivas do examigo de Quain. O próprio jornalista inicia seu discurso com a seguinte fórmula (e a repete pelo menos mais quatro vezes durante o seu relato): "Ninguém nunca me perguntou. E por isso também nunca precisei responder" (Carvalho, 2002 p. 13, 27, 60, 134, 136). As frases expressam a indiferença de quem fala: não há perguntas, não há necessidade de respostas. Negligência típica de quem faz literatura, essa declaração contrasta com o esforço do investigador que busca a verdade, que tenta unir as peças que montarão seu quebra-cabeça, que se lança a aventuras que não desejava viver, seja no meio dos índios Krahô, seja nos Estados Unidos, para compor uma verdade, que acaba tornando-se ficção.

O que impulsiona a escrita num primeiro momento é a dúvida, a curiosidade em relação a uma história que se revelará extraordinária, como costumam ser os romances policiais. O enunciador diz que a antropóloga supôs que ele ia escrever um romance, e ele não a contrariou, o que sugere que ele não tinha muita certeza sobre o gênero textual que estaria compondo. É uma escrita que "independe" de quem a escreve; há papéis, contatos, a montagem de um quebra-cabeça e a criação de uma imagem. Que imagem é essa que a montagem do quebra-cabeça cria? Fiel? Inventada? Mistura de ambas as coisas? A julgar pela maneira dúbia e hesitante como essa imagem escrita se constrói, pode-se dizer que é mais criação do que reconstituição: é uma "combinação de acasos e esforços" que tem como ponto de partida um nome dito em voz alta, pronunciado na voz do enunciador, mas certamente ou um sonho ou um entendimento ou uma certeza de já tê-lo ouvido antes. 
A palavra pronunciada nomeia o objeto da investigação e se apresenta como um signo instável, a começar pela mobilidade do significante: Buel Quain, Bill Cohen, Quain Buele, Cãmtwyon, Cowan.

O narrador coleta uma enxurrada de informações sobre o etnólogo morto, com definições precisas, mas, a todo o momento, sobrevém o incerto: a mãe era uma mulher aflita, as cartas a Heloísa Alberto Torres denunciam uma "estranha ansiedade" e um suposto temor de que alguém a conhecesse e a descobrisse; Quain teria tido uma doença misteriosa; há várias cartas que não foram localizadas pelo que se diz jornalista; os colegas de Columbia especulam se teria sido assassinato ou suicídio. Nada disso é esclarecido no romance. O jornalista transcreve trechos de uma carta de Manoel Perna a Heloísa Alberto Torres que falam em "fontes que reputamos certas" para atribuir o suicídio do etnólogo a razões familiares. E, na carta, Perna dá a entender que as fontes certas são os depoimentos dos índios que conviveram com Quain, o que contradiz o próprio testamento-fantasma do engenheiro, em que ele afirma que a memória naquele lugar não pode ser exumada, que ali não existia verdade ou que as verdades eram múltiplas, portanto instáveis. No quinto texto do romance, o jornalista apresenta uma foto em que as pessoas, quase todas já falecidas, tiveram alguma relação com Buell Quain e levaram suas verdades para o túmulo, contribuindo para as indefinições acerca do homem e de sua história. A memória de um dos poucos vivos que conheceram o etnólogo americano, o professor Luiz de Castro Faria, contribui pouco para a pesquisa, sujeita a "distorções das impressões subjetivas, como a de qualquer um" (Carvalho, 2002, p. 32). Isso inclui, evidentemente, o próprio jornalista, o engenheiro Manoel Perna, os índios e todos aqueles - cientistas ou não que discursam nessa escrita. Tudo o que se diz no romance, portanto, está sujeito às distorções da memória, como no tratamento dado por Lévi-Strauss ao que chamou mito de referência.

Tal mito perde, na linguagem de Lévi-Strauss, o estatuto de referência porque ele próprio é fruto de outros referentes, ou seja, não funciona como ponto de partida. Assim, qualquer outro mito poderia ser a referência, pois não há uma narrativa central. O mito é, então, uma estrutura acêntrica; ele não possui unidade de origem ou de referência. O discurso mito-lógico tem de ser mitomorfo (ter a forma do mito, sem origem, sem referência...). A leitura do mito exige a renúncia ao discurso 
científico ou filosófico, a episteme que busca a origem, o centro, o fundamento, o princípio etc.

A exigência filosófica ou epistemológica do centro é uma ilusão histórica, portanto um mito. Assim, a bricolagem etnográfica é um mitopoema. É possível abandonar toda exigência epistemológica para falar do mito? É possível separar claramente o filosofema-ou-teorema (enunciados ou discursos filosóficos) do mitema-ou-mitopoema (enunciados ou discursos sobre os mitos)? O discurso de Strauss é uma espécie de "sintaxe da mitologia sul-americana" (segundo ele, um pequeno número de frases permite elaborar uma gramática...), jamais um discurso mítico totalizador. A totalização ou é inútil ou impossível, porque seu campo de ação, a linguagem (finita), é um jogo de substituições infinitas. Num sentido clássico, a totalização é impossível pelo fato de termos à disposição do autor uma riqueza infinita, que ele jamais poderá delimitar, enquadrar. Como diz Blanchot: o escritor "possui apenas o infinito, o finito lhe falta, o limite lhe escapa" (Blanchot, 2003, p. 306, tradução nossa). Aqui vigora a lei do excesso. No sentido de jogo, a totalização é interditada porque a linguagem pressupõe o campo de um jogo que a impede: "este campo é com efeito aquele de um jogo, isto é, de substituições infinitas no fechamento de um conjunto finito" (Derrida, 1967, p. 423, tradução nossa). Temos então a lei da carência, materializada pela falta de um centro que controle as substituições e os movimentos do jogo, uma vez que o signo que supre o centro, "esse movimento do jogo, permitido pela falta, pela ausência de centro ou de origem, é o movimento da suplementaridade" (Derrida, 1967, p. 423, tradução nossa). Há sempre algo mais, na "superabundância de significantes em relação aos significados", ou o "excesso de significação", ou seja, há uma falta que se supre sempre e cujo preenchimento é sempre adiado, permanecendo sempre uma lacuna que se quer preencher. A suplementaridade é algo que supre uma falta no signo e nunca o completa.

O que não tem princípio ou centro também não pode ter conclusão ou final, daí a narrativa de nove noites não poder subsistir como "verdade", como "jornalismo". O jornalista tem de se ater a princípios, meios e fins, e o romancista pode, então, agir como o engenheiro, ou enfim é obrigado a isso, e o que se constrói é um relato mito-lógico, mitomórfico, mitopoético, no sentido que Lévi-Strauss atribui a esses termos. O mitopoema, assim, parece guardar alguns traços que o distinguem do filosofema: a parte interna do centro não garante a 
sustentação da estrutura; sua parte externa, os grandes discursos que giram em torno da estrutura, também não garante nem o início nem a investigação nem a conclusão.

É interessante pensar que a repetição ad aeternum do mesmo método de coleta e análise de informações, ou seja, a repetição dos dados manipuláveis dentro do sistema metafísico - cartas, notícias, depoimentos, confidências, fotos - termina por conduzir a narrativa a se esvaziar como possibilidade de verificação, perturbando a segurança do desejo do centro e conduzindo ao final, que não pode ser chamado propriamente desfecho, mas que não deixa de ser surpreendente.

Coincidentemente, tanto no texto de Derrrida quanto no texto de Carvalho, a etnologia parece desempenhar o papel de elemento deflagrador da ruptura. O escândalo de que fala Lévi-Strauss no desacerto entre a oposição natureza $x$ cultura parece se repetir no acúmulo de informações que não conseguem se estruturar para compor a verdade no caso da morte de Buell Quain.

Outra coincidência discursiva interessante, embora não seja determinante de nenhuma conclusão, é a menção ao par bricoleur $\mathrm{x}$ engenheiro no texto de Derrida. Se considerarmos, como Lévi-Strauss o faz, o engenheiro como o criador ou o artista, e o bricoleur como aquele que coleta dados que estão à mão para compor seu discurso, não é destituído de senso associar o engenheiro de Carvalho (o personagem Manoel Perna) ao engenheiro de Strauss. Manoel Perna é a pura emoção, seu discurso solitário não espera nem pretende compor nenhuma verdade tangível, é o mistério, e sua própria existência pode ser considerada uma aporia dentro da lógica do romance; seu interlocutor é alguém inexistente, esperado como o fantasma que assombrava as noites do velho americano que agonizava de câncer na enfermaria onde também morria o pai do jornalista. Um fantasma embutido na afirmação repetitiva: "Isto é para quando você vier" (Carvalho, 2002 p. 7). Pelas indicações de Lévi-Strauss, poderíamos atribuir a atividade de bricoleur ao jornalista, aquele que precisa compor uma verdade com fatos verdadeiros, que giram em torno de um centro fixo interno controlado pelos conceitos externos. $\mathrm{E}$ todo esse levantameno realizado pelo jornalista acaba produzindo um discurso que contém a crítica de si mesmo, em sua percepção, em um dado momento, de que toda referência se esvaiu, a origem se perdeu, a archie absoluta se relativiza e se dilui irremediavelmente. Assim, o bricoleur 
também se torna um engenheiro, e o discurso do jornalista em busca da verdade perde o fundamento, o princípio, para se tornar simplesmente ficção. Afinal, o bricoleur age também como engenheiro, ambos se confundem no texto do romance.

O romance só se declara romance nas últimas páginas. Até então, o gênero romance aparecia aqui e ali como justificativa para as ações do jornalista, para que sua investigação não levasse outrem a inferir que ele estaria brincando com coisas sérias, como a antropóloga que supôs que ele ia escrever um romance, e ele aquiesceu. Quando da visita à tribo Krahô, em busca de depoimentos, ele justifica para um desconfiado indígena que sua investigação não passava de uma brincadeira a que os não índios denominavam romance:

As minhas explicações sobre o romance eram inúteis. Eu tentava dizer que, para os brancos que não acreditam em deuses, a ficção servia de mitologia, era o equivalente dos mitos dos índios, e antes mesmo de terminar a frase, já não sabia se o idiota era ele ou eu (Carvalho, 2002, p. 96).

Supondo que o índio acreditasse nessa justificativa rota, certamente veria no que o branco chamava romance algo tão importante como o mito, ou seja, a verdade do mundo, de seus mistérios, de sua criação. Evidentemente, o índio não acreditou.

Derrida assinala reiteradas vezes a importância do jogo para LéviStrauss, assim como é importante o jogo discursivo no texto de Bernardo Carvalho. Jogo pressupõe tensão. Inicialmente, tensão com a história cúmplice da metafísica teleológica e escatológica, determinação do ser como presença. A história de mãos dadas com a episteme, no sentido de "unidade de um devir, como tradição da verdade ou desenvolvimento da ciência orientado para a apropriação da verdade" (Derrida, 1967, p. 425, tradução nossa). Para Lévi-Strauss, a originalidade interna da estrutura, o respeito que ele devota à estruturalidade, pressupõe uma neutralização do tempo e da história. Curiosamente, entretanto, ele não prescinde de uma

ética da presença, de nostalgia da origem, de inocência arcaica e natural, de uma pureza da presença e da presença a si na palavra; ética, nostalgia e mesmo remorso que ele apresenta frequentemente como a motivação do projeto etnológico quando se reporta às sociedades arcaicas, isto é, exemplares a seus olhos (Derrida, 1967, p. 417, tradução nossa). 
Há, então, duas interpretações das interpretações: uma se move pela necessidade de descobrir uma verdade, buscar uma origem, estabelecer uma explicação segura para as coisas, presença plena, o fundamento tranquilizador, a origem e o fim do jogo. A segunda interpretação da interpretação, de inspiração nietzschiana, procura superar o homem e o humanismo em seu sentido metafísico.

É particularmente importante para nossa reflexão o momento da "conversão" do texto de jornalismo para literatura, em que o fundamento cede definitivamente lugar à superação das verdades humanistas, o que ocorre nas últimas páginas: "A ficção começou no dia em que botei os pés nos Estados Unidos" (Carvalho, 2002, p. 158). A afirmação soa excessivamente categórica para mudar o rumo do discurso, mas não deixa de abalar as expectativas, principalmente caso se considere que a palavra "ficção" pode significar algo em que não se deve acreditar. E a viagem do personagem aos Estados Unidos deveria ser exatamente sua última grande tentativa de elucidar o mistério, considerando que aquele Schlomo poderia ser o filho de Buell Quain, o que, acrescido de mais alguns fatos picantes, "explicaria" o drama e o suicídio do etnólogo, dando à narrativa uma certa verossimilhança dentro da estrutura do romance e, portanto, um desfecho digno do gênero. A conversa do personagem com o americano poderia conduzir a essa conclusão, mas afinal tudo fica no ar, ou melhor, tudo se desmancha no ar, quando o jornalista se encontrava no avião de volta para o Brasil, e o narrador enuncia as últimas palavras do relato:

Nessa hora, me lembrei sem mais nem menos de ter visto uma vez, num desses programas de televisão sobre as antigas civilizações, que os Nazca do deserto do Peru cortavam as línguas dos mortos e as amarravam num saquinho para que nunca mais atormentassem os vivos. Virei para o outro lado e, contrariando a minha natureza, tentei dormir, nem que fosse só para calar os mortos (Carvalho, 2002, p. 168).

Cortar as línguas dos mortos é fazê-los calarem-se para não incomodarem os vivos, para não trazerem seu testemunho aonde não há mais lugar para ele, é dormir para penetrar na noite da literatura, onde os mortos são menos mortos, e os discursos se cruzam e entrecruzam sem necessidade de afirmação ou sustentação de um centro. $\mathrm{O}$ bricoleur e o engenheiro se unem, as interpretações se dispersam, jogando com a afirmação nietzschiana, ignorante da origem, "a afirmação alegre do jogo 
do mundo e da inocência do devir, a afirmação de um mundo de signos sem erro, sem verdade, sem origem, oferecido a uma interpretação ativa" (Derrida, 1967, p. 427, tradução nossa). Sem a verdade do jornalismo, sem a verdade do romance policial (ou não), sem compromisso com o devir, apenas um texto ficcional.

\section{Referências}

BENJAMIN, Walter (1994). Magia e técnica, arte e política. São Paulo: Brasiliense.

BLANCHOT, Maurice (1998). Le livre à venir. Paris: Gallimard.

BLANCHOT, Maurice (1969). L'entretien infini. Paris: Gallimard.

BLANCHOT, Maurice (2003). La part du feu. Paris: Gallimard.

CARVALHO, Bernardo (2002). Nove noites. São Paulo: Companhia das Letras.

DERRIDA, Jacques (1967). L'écriture et la différence. Paris: Éditions du Seuil

Recebido em maio de 2014.

Aprovado em novembro de 2014.

\section{resumo/abstract}

\section{Os discursos do etnólogo, do filósofo e do ficcionista na estrutura do romance Nove noites}

Cid Ottoni Bylaardt

Este artigo pretende colocar em diálogo dois textos: "A estrutura, o signo e o jogo no discurso das ciências humanas", de Jacques Derrida, pensador francês, e Nove noites, de Bernardo Carvalho, romancista contemporâneo brasileiro. O texto de Derrida parece conter as matrizes do pensamento desconstrucionista do filósofo e parte de uma aporia lançada por Claude Lévi-Strauss na dicotomia natureza-cultura para questionar o modelo centrado do pensamento ocidental. Esse escândalo, assim, está ligado à atividade do etnólogo e tem suas origens na etnografia. Este texto procura, então, refletir como a fiçcão se apodera do discurso das ciências humanas para questioná-la, num movimento semelhante ao pensamento de Derrida na interpelação permanente do desconstrucionismo ao discurso científico. A narrativa, que de início parecia conduzir para a 
resolução de um crime, à guisa de romance policial ou relato jornalístico, frustra as expectativas do leitor, terminando por diluir o que parecia ser a trajetória segura de uma estrutura montada em torno de um firme centro.

Palavras-chave: jogo, desconstrução, verdade, ficção.

\section{The ethnologist's, the philosopher's and the ficcionist's discourses in the novel Nove noites}

\section{Cid Ottoni Bylaardt}

This paper intends to establish a dialogue between two texts: "Structure, Sign and Play in the Discourse of Human Sciences", by Jacques Derrida, and Nove noites [Nine nights] by the Brazilian contemporary novelist Bernardo Carvalho. Derrida's text seems to hold the origins of the deconstructionist thinking of the philosopher, and begins with an aporia pointed by Lévi-Strauss in the binary pair nature-culture to discuss the centered model of the occidental thinking. This scandal, thus, is associated to the activity of the ethnologist and has its roots in ethnography. This text seeks, therefore, to reflect upon how the fiction seizes the discourse of human sciences in order to put it in question, in a movement similar to Derrida's thinking in the permanent deconstructionism's interpellation to the scientific discourse. The narrative, which at first seemed to lead to the solution of a crime, like in a detective story, frustrates the reader's expectations, dissolving what seemed to be a consistent trajectory of a structure erected around a solid center.

Palavras-chave: game, deconstruction, truth, fiction. 